\title{
DEZ ANOS DE AÇÕES E INOVAÇÕES DO CENTRO BRASILEIRO COLABORADOR DA OMS PARA O DESENVOLVIMENTO DA PESQUISA EM ENFERMAGEM
}

Isabel Amélia Costa Mendes*

No contexto contemporâneo de globalização do mundo do trabalho, a força propulsora da economia reside na educação, na pesquisa e no conhecimento desta resultante. Nestes termos, a posse de informação e de conhecimento, aliada à utilização do capital humano, caracteriza o cerne da organização econômica e social. Não é por acaso que estamos vivendo a chamada era do conhecimento.

Por isso, os diferentes tipos de organizações - inclusive os de serviço, como as instituições acadêmicas - passam a ser moldados por forças oriundas de informação. Em conseqüência, aquelas que melhor utilizarem, distribuírem e incorporarem informação e conhecimento, envolvendo seus recursos humanos em todos os setores, terão maior vantagem competitiva e colaborativa.

Nesta perspectiva é que a Escola de Enfermagem de Ribeirão Preto da Universidade de São Paulo, enquanto Centro Colaborador da Organização Mundial da Saúde para o desenvolvimento da Pesquisa em Enfermagem, tem se comportado como uma organização de serviço em constante mobilização para equipar-se e adaptar-se de modo a corresponder e atuar frente a este mundo cada vez mais interligado.

Este ano de 1998, em que comemoramos o $10^{\circ}$ aniversário deste Centro Colaborador, enseja uma reflexão para que no momento presente reverenciemos o passado e celebremos o futuro com uma visão de desenvolvimento de potencialidades dos recursos humanos, com expectativas de adoção de inovações e de atitudes pró-ativas para que o próximo decênio deste Centro possa fomentar ainda mais a conectividade entre pesquisadores e instituições, de modo que o conhecimento disseminado por intermédio da Revista Latino-Americana de Enfermagem flua na rapidez que a sociedade está a exigir.

* Diretora da Escola de Enfermagem de Ribeirão Preto da Universidade de São Paulo, Centro Colaborador da OMS e Presidente do Conselho Diretor da Revista Latino-Americana de Enfermagem 
DIEZ AÑOS DE ACCIONES E INNOVACIONES DEL CENTRO BRASILEÑO COLABORADOR DE LA OMS PARA EL DESARROLLO DE LA INVESTIGACIÓN EN ENFERMERÍA

En el contexto contemporáneo de la globalización del mundo del trabajo, la fuerza propulsora de la economía reside en la educación, en la investigación y en el conocimiento de esta resultante. En estos términos, la poseción de información y de conocimiento, junto con la utilización del capital humano, caracteriza el fundamento de la organización económica y social. No es por casualidad que estamos viviendo la llamada era del conocimiento.

Por eso, los diferentes tipos de organizaciones - inclusive los de servicio, como las instituciones académicas - pasan a ser moldeados por fuerzas generadas en la información. En consecuencia, aquellas que mejor la utilicen, distribuyan e incorporen información y conocimiento, intergrando sus recursos humanos en todos los sectores, tendrán mayor ventaja competitiva y colaborativa.

En esta perspectiva es que la Escuela de Enfermería de Ribeirão Preto de la Universidad de São Paulo, como Centro Colaborador de la Organización Mundial de la Salud para el desarrollo de la Investigación en Enfermería, se ha comportado como una organización de servicio en constante movilización para equiparse y adaptarse de tal forma que pueda corresponder y actuar frente a este mundo cada vez más interligado.

Este año de 1998, en que conmemoramos el $10^{\circ}$ aniversario de este Centro Colaborador, estamos llamando a hacer una reflexión para que e el momento presente reverenciemos el pasado y celebremos el futuro, con una visión de desarrollo de potencialidades de los recursos humanos, con expectativas de adopción de innovaciones y de aptitudes proactivas; para que el próximo decenio de este Centro, pueda fomentar aún más la conectividad entre invetigadores e instituciones, de modo que el conocimiento diseminado por intermedio de la Revista Latino-Americana de Enfermería, fluya a la rapidez que la sociedade está exigiendo.

\footnotetext{
* Directora de la Escuela de Enfermería de Ribeirão Preto de la Universidad de São Paulo, Centro Colaborador de la OMS y Presidente del Consejo Directivo de la Revista Latino-Americana de Enfermería
} 